\title{
DESIGN OF RESONANT CONTROLLER SYSTEM CONNECTED WITH OIL EXTRACTION MACHINE
}

\author{
M. M. Badr
}

ABSTRACT

In recent years, the absolute acceptance of biodiesel as an alternative fuel and lubricant has rapidly grownup in worldwide accompanied by decrease raw materials of fossil oil as well risks related by highly carbon content for the exhaust gases emissions. It is expectant that biodiesel production will be taking status more importantly in the coming years, as such, extraction processes and production plan will be more critical than ever in particular with provide database about vegetable oils characteristics because these oils especially jojoba oil is one of the most important sources for making biodiesel. Current study aims a resonance technique application assisted mechanical extraction on jojoba oil recovery with a view to purpose optimizing machine efficiency, power produced and heating value for jojoba oil during the entire process. An extremely important property of this design is ability to oscillation at a certain frequency, so a control unit was linked to operate this technique which allows to change the value of capacitance on different frequencies in designed circuit. The experiments were executed to detect the effect of studied parameters like resonance frequency levels $(60,70,80$ and $90 \mathrm{kHz})$ and extraction speeds of press screw (40, 45, 55 and $65 \mathrm{rpm})$ on evaluation indicators through a resonance technique application as well as has been presented a comparison among some main indicators for jojoba oil and fossil fuel specifications. The obtained results evidenced highly significant differences $(P<0.01)$ among frequency levels, extraction speed and their interaction for all evaluation indicators. Machine efficiency of $95.23 \%$ was reached for resonance treated sample at $80 \mathrm{kHz}$ frequency level and extraction speed of $55 \mathrm{rpm}$ when compared to $75.00 \%$ for control sample with improves the extraction yield by $34.30 \%$. Furthermore, produced power and heating value were $1306 \mathrm{~kW}$ and $4701 \mathrm{MJ} . \mathrm{h}^{-1}$ under the same pervious conditions.

\footnotetext{
${ }^{*}$ Assistant professor of Agric. Eng., Fac. of Agric., Zagazig Univ. Egypt.
} 


\section{INTRODUCTION}

7 he inspect off a renewable source have been going on for decades to meet our energy requirements boosted by an inescapable reality that the global fossil fuel reserves will be deplete soon. The potential solution to get out of this crisis is dependence on biofuels as one of the sources of renewable energy. At recent years, an interest has been turned toward the jojoba oil that can be planted and is renewed as well is more neutral for carbon hence, it burns further cleanly without pollution of the environment as and is achieves more effective compared with conventional fossil fuel, and that puts it in its best position especially with inadequacy of the other vegetable oils. Biodiesel oil is obtained by transesterification process that converts oils and fats into biodiesel and glycerin. The production of biodiesel passes through many stages, this study was focused on extracting process followed by refining oil as an important first step in the process of preparing the biodiesel. Oil extraction procedure depends on the seeds being used, type of oil extracted and its characteristics and quality. Mechanical extraction regards the most common process for oil extraction which includes the application of continual pressure using screw press to compel oil out of the seeds. Mechanical extraction technique is a more convenient method for both small and large throughput, this as a result of the economic operating in comparison with the other extraction processes.

Recent, some new techniques have been offered with a view to improve the oil extraction procedure by optimizing the oil recovery yield. These techniques used in many applications are rested on ultrasounds and microwaves (Clodoveo and Hbaieb, 2013). The extraction process will support the sequent phases by resonance frequency technique, which considered a key pillar of the biofuel production process from jojoba oil extracted. A resonance technicality is an integration of an electric and a mechanical energy and on this basis, it is originating vibratory effect across different frequencies Which are probably to be exploited in the several of engineering fields to improve the performance rate and enhance efficiency of an oil extraction, coincidingly with the major progress in the industrial sector. The vibration systems could be enhancing the seed cells breakage as well improve efficient the oil extraction procedure through avoiding the 
adverse traces on the entire process owing to the use of the other extraction methods. In the olive paste samples under vibration system was observed an increment in the extraction efficiency of about 53\% during resonant condition (Toschi et al., 2013).

Frequency bands affect viscous liquids treatment during mechanical extraction process, which is mainly associated to the piezoelectric effect. This frequency is transmitted through a series of compression and decompression effects induced on the molecules of the extracted oil (Jambrak et al 2012). When providing a required frequency, the rarefaction phase overrun the attraction forces of the liquid and cavitation form existing within the fluid particles. These obtained bubbles are spread everywhere inside the liquid, create during the period of a few phases to critical size until turn unstable and breakdown strongly (Amin et al 2015). The breakdown of rarefaction bubbles procures to energy collections in hot sites, generating excess temperatures and pressures which achieve in turn high shear effect of energy waves in the rarefaction zone. The combination of previous factors pressure, heat and frequency has an assortment of efficient effects on the used system (Soria and Villamiel 2010). It is worth mentioning the chief relationship between energy content and oil yield recovery must be consider to maximize the strategy of alternative energy sources, especially when jojoba oil is used as an alternative renewable energy source. The calorific value of jojoba oil is approximately 42.40 $\mathrm{MJ} / \mathrm{kg}$, which status as important among the vegetable oils beside that extraction by-products have a calorific value of $15.34 \mathrm{MJ} / \mathrm{kg}$ (Al-Hamamre and Rawajfeh, 2015). Whereas, the investigation of the cited technique in the extraction process is novel procedure and few researches were appropriated to these subjects. In order to make improvements on the extraction procedure and to raise extraction efficiency by using a resonance technique under different frequency rates during jojoba oil extraction, that could be worthwhile in this new technological field. Therefore, the present study was carried out with a view to improve an effectiveness of the mechanical extraction by using resonant frequency technique as a more effective dual procedure by optimizing the oil recovery yield. The detailed objectives of this study can be illustrated as follows: design a resonance frequency circuit equipped by controller unit, maximize operating 
parameters under resonant condition and their affecting on the performance of the developed machine and evaluation of machine in terms of extraction efficiency as well the energy content and produced power.

\section{MATERIAL AND METHODS}

The experiments were conducted the applicability of a resonance frequency technique in oil extraction machine of jojoba seeds followed by refining unit. Where the jojoba oil regards a promised energy source that can be used as a biofuel in many industrial applications. A resonant technique, study subject, is a combination of an electric and a mechanical energy which generates oscillating effect at different frequencies which can be applied in the field of processing engineering to improve the performance rate and enhance efficiency of an extraction machines.

\section{The developed machine:}

The extraction machine of jojoba oil was modified to have the following components as shown in Fig. 1; seeds hopper, a modified screw with variable threads installed on conical shaft, a resonant unit, oil filtration unit, a cake drainage cone, electric motor and planetary gearbox.

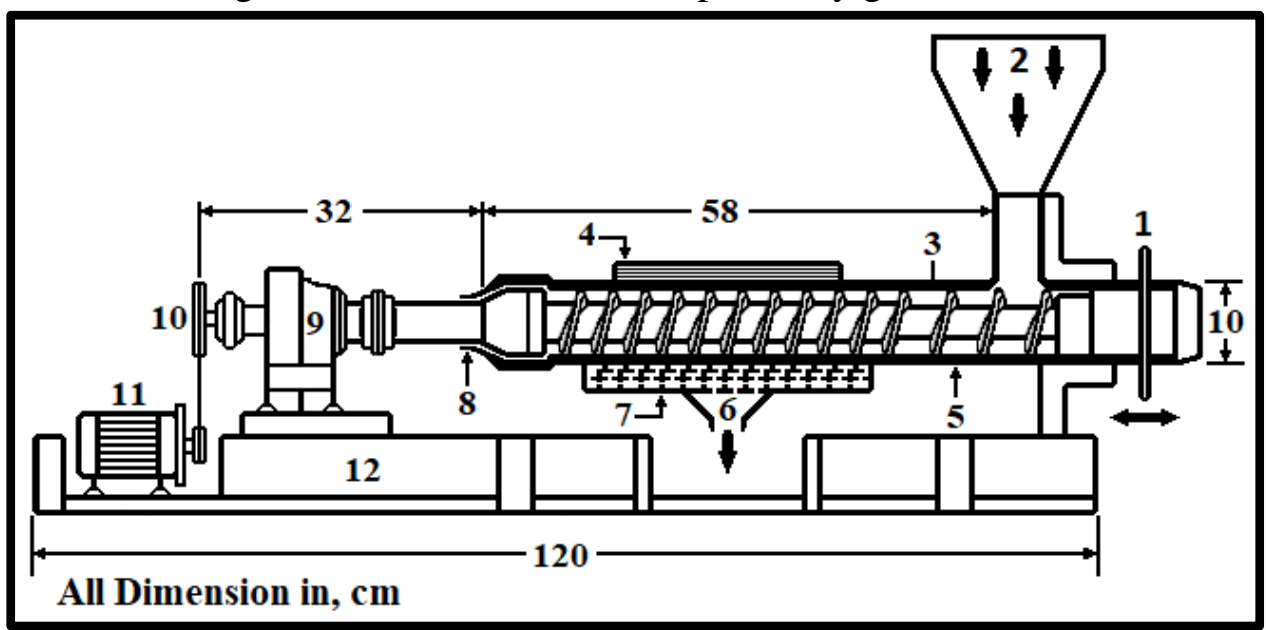

\begin{tabular}{|c|l|c|l|}
\hline \hline No. & Part Name & No. & Part Name \\
\hline 1 & Pressing Assembly & 7 & Filtration Unit \\
\hline 2 & Feeding Hopper & 8 & Cake Drainage \\
\hline 3 & Press Screw & 9 & Planetary Gearbox \\
\hline 4 & A Resonant Unit & 10 & Pulleys and Belt \\
\hline 5 & Press Barrel & 11 & Electric Motor \\
\hline 6 & Oil Outlet & 12 & Main Frame \\
\hline
\end{tabular}

Fig. 1: Structure of the developed extraction machine. 
A power screw is a drive tool used in extraction machinery to convert a rotary motion into a linear motion for power transmission, it produces uniform motion and normally uses variable threads and conical shaft. Power screws should be selected for smooth and noiseless transmission of power with an ability to carry heavy loads with high efficiency. Fig. 2 presents the modified screw with a resonant unit and filtration unit.

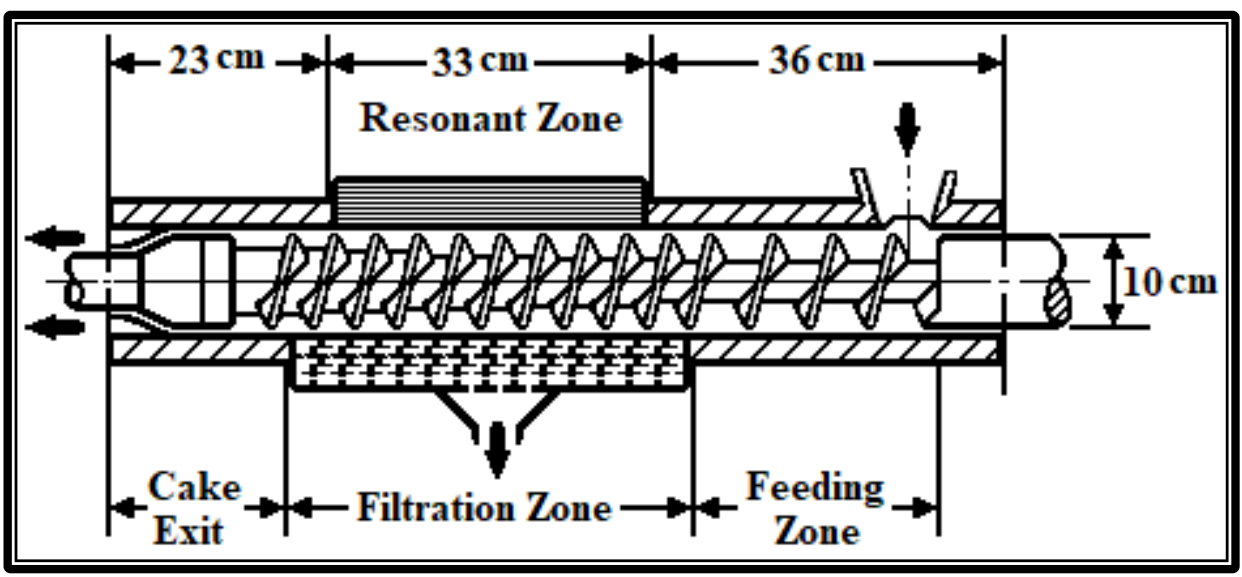

Fig. 2: Schematic diagram of a modified screw with a resonant unit. A resonant circuit, RLC circuit is an electric circuit consisting of a resistance, an inductor and a capacitor connected in series form at the two ends of supply voltage, this configuration modes a harmonic oscillator as shown in Fig. 3.

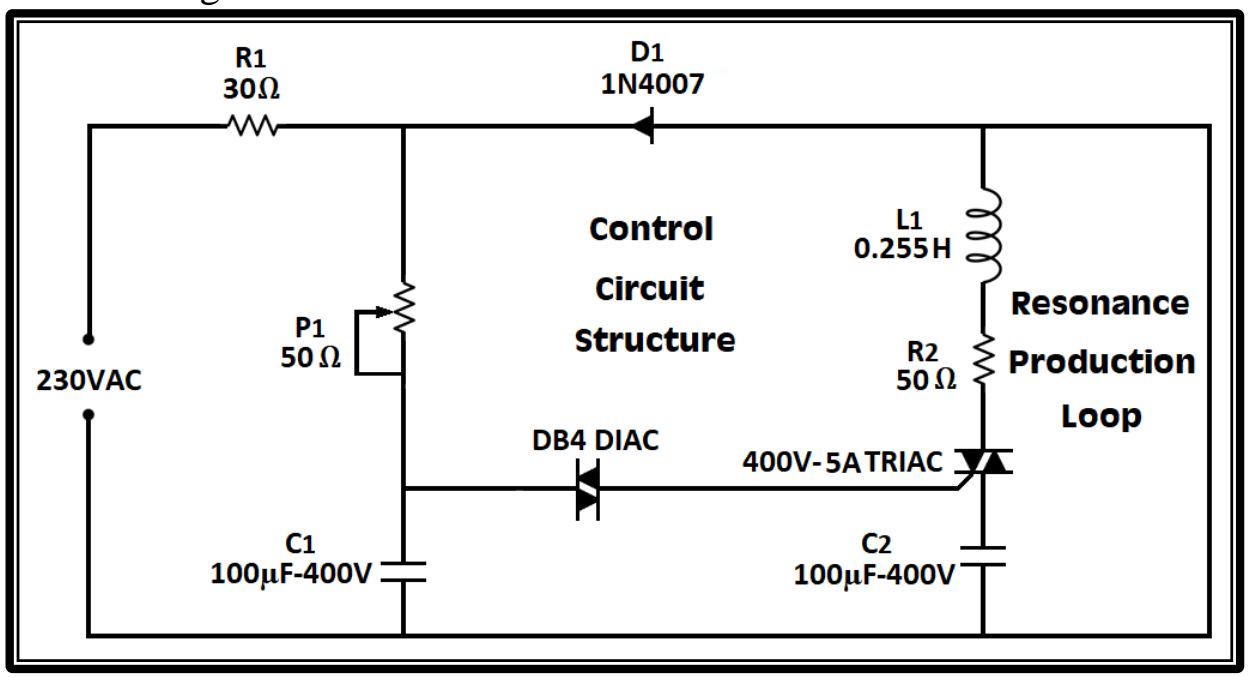

Fig. 3: Schematic diagram of a resonance circuit with controller unit. 
The circuit name is inspired by the first letters for the incorporation components in this circuit. Series RLC circuits are a second order circuits due to they include two energy store elements, a capacitance and an inductance. In addition to generate oscillation frequencies can be also controlling values of frequency output using the indicated circuit in the previous figure. Accordingly, this design has been enforced to achieve a constant oscillations output at each state under different load conditions.

\section{Methods}

A resonant effect is the property of an electromechanical energy conversion by which an electric charge generates a mechanical force, this effect applied to the expelling machine leads to increase both pure oil yield and extraction efficiency. The study was executed to develop and evaluate the performance of an expelling machine for extracting of crude oil from jojoba seeds. The designed machine has a developed effective an oscillation frequency system using resonant circuit supplied with controller unit that provide for efficient operation at lower speeds and produce a high amount of crude oil compared to the standard extraction machines.

\section{Design of a resonance circuit:}

In this study, the expelling machine was developed with the provision of a fine control unit in the oscillator frequency output under the different operating conditions, where the control circuit is designed using the semiconductor switching elements (triac and diac). The triac is used in synchronism with the diac to achieve full wave control of the AC voltage supply in controller systems. This unit conduct as controlled switch and can fulfill the functions of controlled regulation, rectification and inversion of load power, as can connect current from any polarity of a voltage supply.

\section{A resonance circuit analysis:}

The amount of current is one of the basic criteria for selecting electronic elements inside the designed resonant circuit, in addition to the equivalent impedance and dropping voltage across each element. Hence, it must be maintained the circuit elements from over-current, so it is required this design to accurate description of each electrical quantity such as: the current intensity, equivalent impedance and dropping voltage. The equivalent electric circuit for the oscillator device shows a series RLC circuit, which produces the electromechanical vibrations during the 
operation of the oil expelling machine. When analyzing this circuit, must be taken into considered the magnitude of both $\mathrm{X}_{\mathrm{L}}$ and $\mathrm{X}_{\mathrm{C}}$ to find the total circuit impedance, $\mathrm{Z}$. The equivalent impedance has a series oscillation where capacitor resonates with inductor at the operating frequency this oscillation is the series frequency.

$$
\begin{gathered}
\mathrm{X}_{\mathrm{L}}=2 \pi f \mathrm{~L}=80.07 \Omega \\
\mathrm{X}_{\mathrm{C}}=\frac{1}{2 \pi f \mathrm{C}}=15.92 \Omega \\
Z=\sqrt{\mathrm{R}^{2}+\left(\mathrm{X}_{\mathrm{L}}-\mathrm{X}_{\mathrm{C}}\right)^{2}}=144.96 \Omega
\end{gathered}
$$

Where: $\mathrm{X}_{\mathrm{L}}$ and $\mathrm{X}_{\mathrm{C}}=$ inductive and capacitive reactance's. $f=$ electrical frequency equal $50 \mathrm{HZ}$.

$\mathrm{L}$ and $\mathrm{C}=$ an inductance and a capacitance each of inductor and capacitor. $\mathrm{Z}$ and $\mathrm{R}$ are the total equivalent impedance and the resistance value of the designed circuit.

The series RLC circuit has a singular loop with the instantaneous electric current flowing within the circuit is the same for each loop elements. Whereas the capacitive and inductive reactance's $X_{L}$ and $X_{C}$ are function of the supply frequency, the circuit response will hence differ with frequency, $f$. In that case the voltage drops both for $\mathrm{R}, \mathrm{L}$ and $\mathrm{C}$ across the defined circuit elements. The extent of the source voltage via three components in a series circuit is formed of the three individual part voltages as shown $V_{R}, V_{L}$ and $V_{C}$ with the current common for the circuit elements.

$$
\boldsymbol{V}_{\boldsymbol{s}}=\sqrt{\boldsymbol{V}_{\boldsymbol{R}}^{2}+\left(\boldsymbol{V}_{\boldsymbol{L}}-\boldsymbol{V}_{\boldsymbol{C}}\right)^{2}}
$$

Where: $V_{S}=$ voltage amplitude of the source.

$\mathrm{V}_{\mathrm{R}}, \mathrm{V}_{\mathrm{L}}$ and $\mathrm{V}_{\mathrm{C}}=$ The instant voltage across a resistor, an inductor and a capacitor, respectively. The current rating, I that flow across this circuit can be calculated by the following equation.

$$
I=\frac{V_{s}}{Z}=1.59 \mathrm{~A}
$$

As it mentioned above that the current has the same value in each the components of a series circuit. Therefore, the voltage via each element can also be characterized mathematically based on the current flowing through each element as follows.

$$
V_{R}=I . R=206.70 \mathrm{~V}
$$




$$
\begin{gathered}
V_{L}=I . X_{L}=127.31 \mathrm{~V} \\
V_{C}=I . X_{C}=25.31 \mathrm{~V}
\end{gathered}
$$

Hence, can be conclude from the previous analysis of the resonance circuit that the circuit elements are selected to support values higher than the calculated instant voltage and a current flowing across circuit. According to the results of a resonance circuit analysis, the specifications of each triac, diac, capacitor and diode were chosen to be supporting 400V and 5A these values are greater than calculated values to ensure and protect all electronic elements within a resonance circuit.

\section{An operating theory of a resonant controller circuit:}

The triac and diac elements-based frequency controller circuit is designed for adjusting the oscillator frequency of resonant unit. This frequency can be adjusted by exchanging the setting of potentiometer, $\mathrm{P}_{1}$. The circuit incarnates a self-stabilizing control that conserves the frequency output of the resonant unit under different loading states. When, the potentiometer value is decreased in the resonant unit as a result, the current increase in $\mathrm{R}_{1}$ and $\mathrm{C}_{1}$ that causing the triac to be induced and the oscillator frequency output increases accordingly and vice versa.

Main 230VAC is passed across 30-ohm resistor, $\mathrm{R}_{1}$ and 50-ohm potentiometer $\mathrm{P}_{1}$, the output of this resistance is coupled in the terminal of $100 \mu \mathrm{F}$ capacitor, $\mathrm{C}_{1}$ to be charged that flows to a certain direction through diac and triac for adjusting and stabilizing the oscillator frequency. The resonance frequency is produced via series RLC circuit which includes both 50 -ohm resistor, $\mathrm{R}_{2}, 0.255 \mathrm{H}$ inductor, $\mathrm{L}_{1}$ and $100 \mu \mathrm{F}$ capacitor, $\mathrm{C}_{2}$. these components are used to produce and control the appropriate frequency values during the machine operation of oil extraction. It should be noticed that the frequency values can be regulated using the controller circuit from 5 to $100 \mathrm{kHz}$ during oil extraction process.

\section{Operating principle of developed machine:}

The principal aim of machine development is produced efficient pressure force for extracting jojoba seeds oil using a resonance technique with frequency controller followed by refining unit. This procedure has a hopper for feeding jojoba seeds, which enters inside the modified screw chamber with variable threads installed on conical shaft as presented in Fig. 1 and 2, where the press moves the seeds towards the die from feeding zone to press 
zone takes place under the effect of a resonance frequency that is produced via series RLC circuit with the possibility of adjust and stabilizing the oscillator frequency as shown in machine structure of part 4 . The expelled oil is collected at the oil outlet of part 6 and the pressed cake is collected at the die opening in part 8. Oil discharge zone was supplied with filtration unit as shown of part 7 , and it is far from the cake drainage zone until the pressure reaches its maximum as well as obtainment a pure crude oil. This machine is improved using a resonance frequency technique equipped with controller unit as a development over existing machine.

\section{Measurements and determinations:}

Evaluation of the performance of the developed machine for extracting jojoba seeds oil was based on the following indicators:

\section{Oil extraction rate:}

The extraction rate quantifies the weight of crude oil, $\mathrm{w}_{\mathrm{o}}$ that the machine is capable of expelling per unit time using the following equation.

$$
E R=\frac{W_{o}}{t}
$$

\section{Extraction efficiency:}

It is obtained from weight of crude oil collected to weight of oil content, Oc in the experimental seeds, which is offered by;

$$
\eta_{\mathbf{m}}=\frac{\mathbf{W}_{\mathbf{o}}}{\mathbf{0}_{\mathbf{c}}} \times \mathbf{1 0 0}
$$

Therefore, the oil content in the experiment seeds is calculated by a weight of the seeds processed, $\mathrm{W}_{\mathrm{s}}$ and oil content percentage of jojoba seeds, $\mathrm{C}_{\mathrm{P}}$ which was valued of $45 \%$.

\section{Heating value:}

$$
\boldsymbol{O}_{c}=W_{s} \cdot C_{P}
$$

The specific heating value is based on higher calorific value of Jojoba oil, $\mathrm{HCV}$ and oil extraction rate, which can be calculated by unit joule per hour as shown the following equation.

$$
\mathrm{HV}=\mathrm{HCV} \times \mathrm{ER}
$$

The high heating value can be expressed by the amount of heat produced through the complete combustion of a unit quantity of fuel. The high

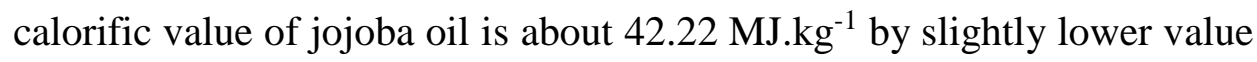


than fossil fuel and which was presented through physicochemical properties of the tested samples.

\section{RESULTS AND DISCUSSION}

The effects of resonance frequency on oil extraction rate, machine efficiency, heating value and produced power were discussed in this section measured at different extraction speeds. Furthermore, it includes the maximize of process parameters based on the study objectives specified for each response variable by using resonance technology. The obtained results and discussion have been offered successively under the following items.

\section{The main indicators of fuel specification}

Biofuel source of energy can reduce to limit the reliance on fossil fuel, hence utility maximization of those sources is imperative especially in recent times. Measured characterizations of jojoba oil is very significant to provide a more accurate database particularly, when compared to both diesel and gasoline fuel, according to (Staffell 2011) Which is given a more developed concept of the alternative energy sources. The results of physicochemical properties are offered in Tables 1, that shows the specific gravity, viscosity, heating value, flash point, carbon residue, sulfur content and ash content of the test samples randomly.

Table 1. Physicochemical properties of jojoba oil and fossil fuel.

\begin{tabular}{lccc}
\hline \multicolumn{1}{c}{ Property } & Gasoline & Diesel & Jojoba oil \\
\hline Density, $\mathrm{kg} \cdot \mathrm{m}^{-3}$ at $25{ }^{\circ} \mathrm{C}$ & 741 & 837 & 863 \\
Viscosity, $\mathrm{mm}^{2} \cdot \mathrm{s}^{-1}$ at $40{ }^{\circ} \mathrm{C}$ & 0.550 & 4.00 & 24.75 \\
Heating value, $\mathrm{MJ}_{\mathrm{kg}}{ }^{-1}$ & 46.94 & 45.60 & 42.22 \\
Flash point, ${ }^{\circ} \mathrm{C}$ & -45 & 74 & 275 \\
Carbon residue, $\%$ & 10 & 12 & 0.012 \\
Sulfur content, $\mathrm{mg} \cdot \mathrm{kg}^{-1}$ & 10.00 & 10.00 & 0.00 \\
Ash content, $\%$ & $0.1-0.2$ & $0.1-0.2$ & 0.00 \\
Refractive index at $25{ }^{\circ} \mathrm{C}$ & 1.501 & 1.465 & 1.459 \\
PH value & $7.00-8.00$ & $5.50-8.00$ & $6.95-7.34$ \\
\hline
\end{tabular}

Specific gravity is one of the more significant physical properties so that the most other properties can be related with its density, it is able to supply information around fuel quality, power output and exhaust emissions. Whenever increased the density led to increase power output. It can also 
achieve a lower emission levels at the same time and this enhances the use of biofuels. The previous values between calorific value of Jojoba oil is too similar to those both diesel and gasoline fuels. Which provides the appropriate alternative in case of use jojoba oil as an energy source compared to fossil fuel. It is worth mentioning the higher flash point temperature makes jojoba oil is safer of both diesel and gasoline fuels.

\section{Analysis of variance}

Analysis of variance was performed using SPSS (version 16) least significantly differences were calculated at probability $0.01 \%$. Highly significant differences were found among a resonance frequency levels, extraction speed and their interaction for all evaluation indicators as shown in Table 2. The main effect mean squares measure indicates that the evaluation indicators were more affected by resonance frequency than extraction speed or their interaction.

Table 2. Analysis of variance (mean squares presented) of the resonance frequency levels at different extraction speeds.

\begin{tabular}{|c|c|c|c|c|c|}
\hline Source of variation & D.F. & $\begin{array}{l}\text { Extraction } \\
\text { rate, } \mathrm{kg} \cdot \mathrm{h}^{-1}\end{array}$ & & $\begin{array}{c}\text { Machine } \\
\text { efficiency, \% }\end{array}$ & \\
\hline Frequency & 3 & 8759.50 & $* *$ & 795.21 & ** \\
\hline Speed & 3 & 609.11 & $* *$ & 100.27 & ** \\
\hline Frequency*Speed & 9 & 25.98 & $* *$ & 2.15 & ** \\
\hline Error & 30 & 0.06 & & 0.08 & \\
\hline Total & 47 & 603.01 & & 57.62 & \\
\hline Grand Mean & & 64.13 & & 82.11 & \\
\hline Source of variation & D.F. & $\begin{array}{c}\text { Heating value, } \\
\text { MJ.h }^{-1}\end{array}$ & & $\begin{array}{c}\text { Produced } \\
\text { Power, kW }\end{array}$ & \\
\hline Frequency & 3 & 15610000 & $* *$ & 1205208 & ** \\
\hline Speed & 3 & 1085616 & $* *$ & 83694 & ** \\
\hline Frequency*Speed & 9 & 46303 & ** & 3576 & ** \\
\hline Error & 30 & 110.73 & & 9 & \\
\hline Total & 47 & 1074836 & & 82961 & \\
\hline Grand Mean & & 2707.60 & & 752.19 & \\
\hline
\end{tabular}

Moreover, the analysis contrasts indicated that increasing a resonance frequency levels of 60, 70, 80 and $90 \mathrm{kHz}$ a highly significant response (P 
$<0.01)$ for oil extraction rate, machine efficiency, heating value and produced power measured at different extraction speeds of 40, 45, 55 and $65 \mathrm{rpm}$ during oil extraction process by using resonance technology.

\section{LSD comparisons test}

The results obtained of least significantly differences (LSD) exhibited that highly significant differences among most a resonance frequency levels measured at different extraction speeds in respect of oil extraction rate, machine efficiency, heating value and produced power.

\section{Oil extraction rate and machine efficiency}

Representative values of both oil extraction rate and machine efficiency versus a resonance frequency at different extraction speeds are given in Figs. 4 and 5. It is clear that extraction rate and machine efficiency were highly significant increased by increasing frequency level to a certain level, any further increase in a resonance frequency will decreased both an oil extraction rate and machine efficiency.

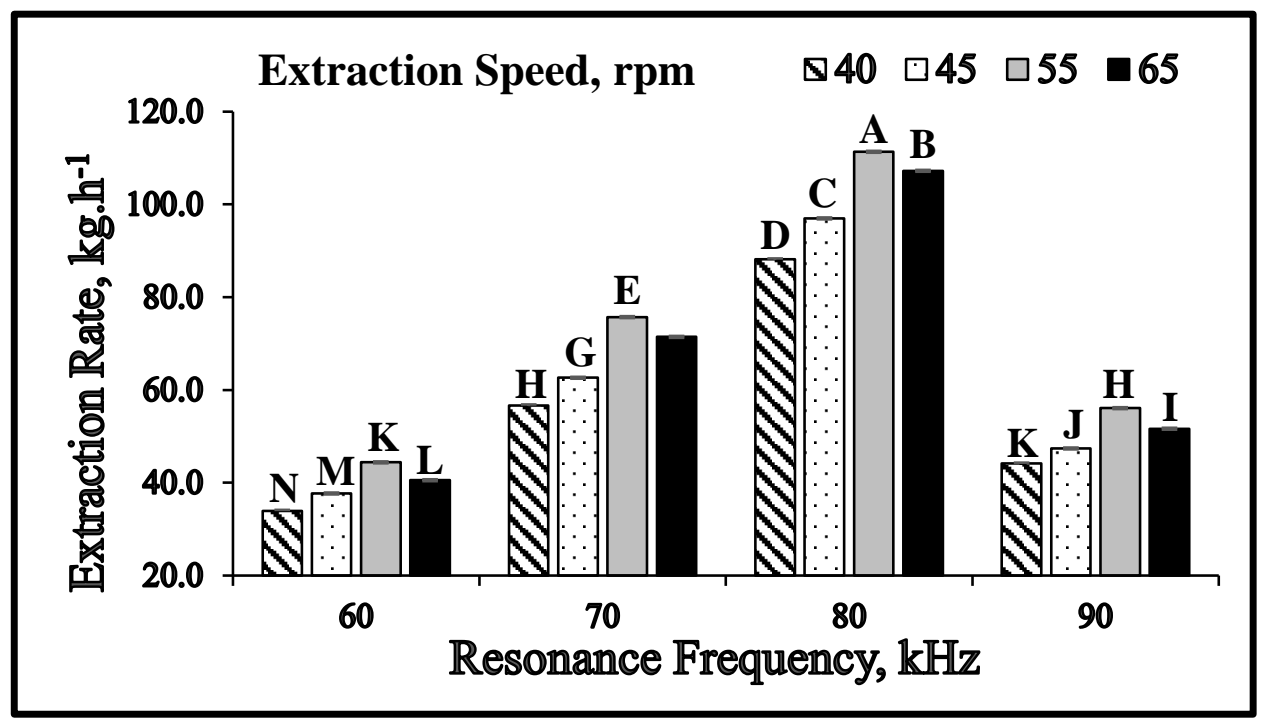

Fig. 4: Effect of resonance frequency levels on extraction rate. Vertical bars represent the LSD $(P<0.01)$, differences between means with the various letter are highly significant.

It was noticed that the highest values of oil extraction rate were (88.16, $96.99,111.35$ and $107.25 \mathrm{~kg} \cdot \mathrm{h}^{-1}$ ) at frequency level of $80 \mathrm{kHz}$, while the lowest values recorded $\left(33.96,37.69,44.40\right.$ and $\left.40.55 \mathrm{~kg} . \mathrm{h}^{-1}\right)$ at frequency level of $60 \mathrm{kHz}$ under extraction speeds of 40, 45, 55 and $65 \mathrm{rpm}$ 
respectively. On the other hand, the highest values of machine efficiency were $(89.31,92.26,95.23$ and $90.82 \%)$, whilst the lowest values reached $(70.45,72.95,75.22$ and $71.58 \%)$ under the same pervious conditions.

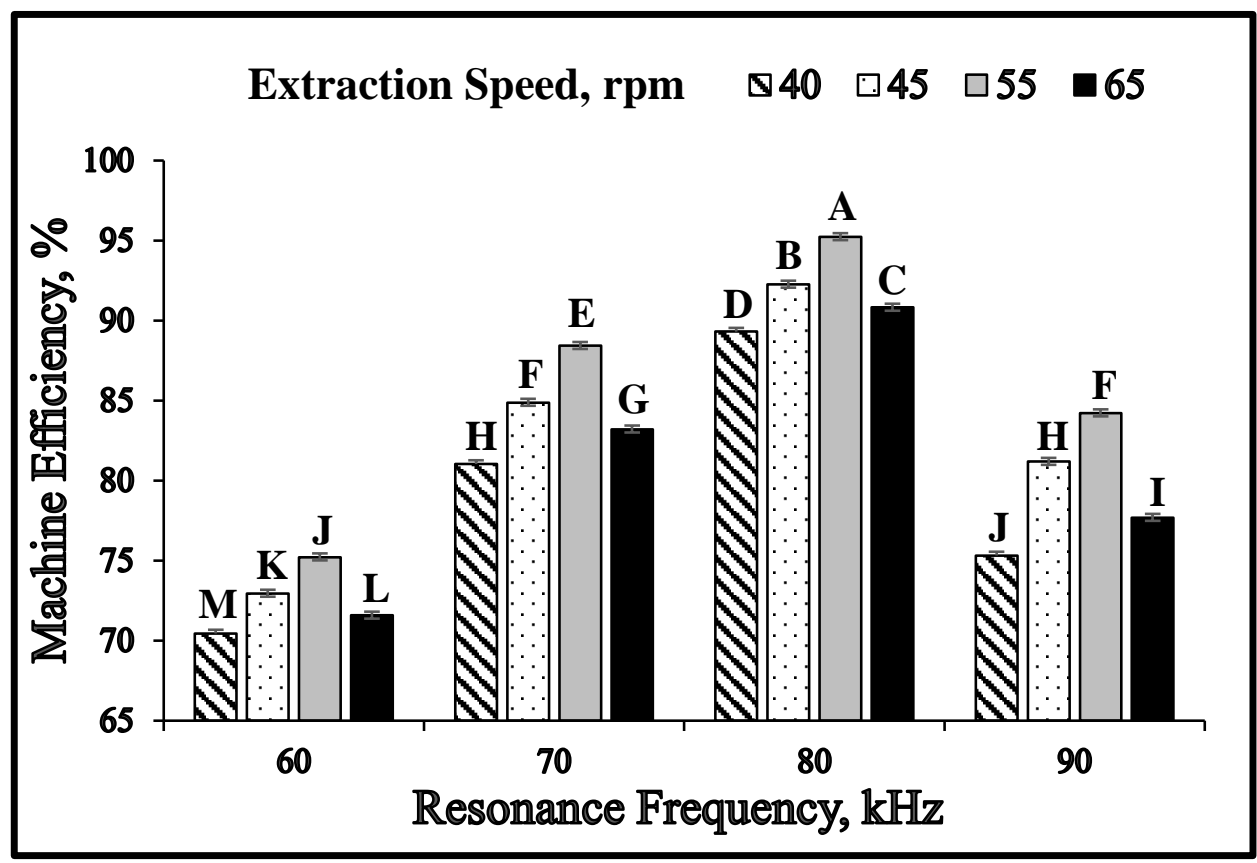

Fig. 5: Effect of resonance frequency levels on machine efficiency under the same differences between means.

Higher values of resonance frequency levels more than the optimum value tend to decrease both oil extraction rate and overall machine efficiency because the forward motion of oil flow towards the exit opening is lower than reverse direction causing material of high viscosity is created which leads in increase oil losses in cake as well as decrease refinement grade.

Lower values of frequency levels less than the optimum value had the same previous effect as a result to increase materials thickness on the surface of press screw that will take longer time during extraction process and thus a lot of oil will leave the extraction zone and is exited from cake opening without well refining.

\section{Heating value}

With regard to influence of resonance frequency on the heating value at different extraction speeds is presented in Fig. 6. The obtained results are evidence that heating value was high significantly increased by increasing 
resonance frequency up to suitable level therefore, study treatments of low frequency levels had decreasing the heating value a same tendency at high frequencies compared with an appropriate-frequency treatment. Variance of the heating value results were highly significant $(\mathrm{P}<0 \cdot 01)$ in which the

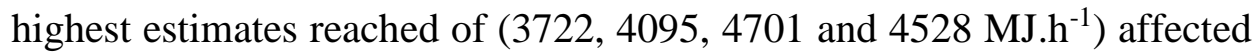
by resonance frequency level is worth $80 \mathrm{kHz}$. Whereas a frequency level of $60 \mathrm{kHz}$ recorded the lowest estimates of heating values of $(1434,1591$,

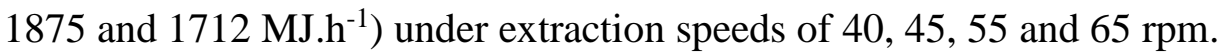

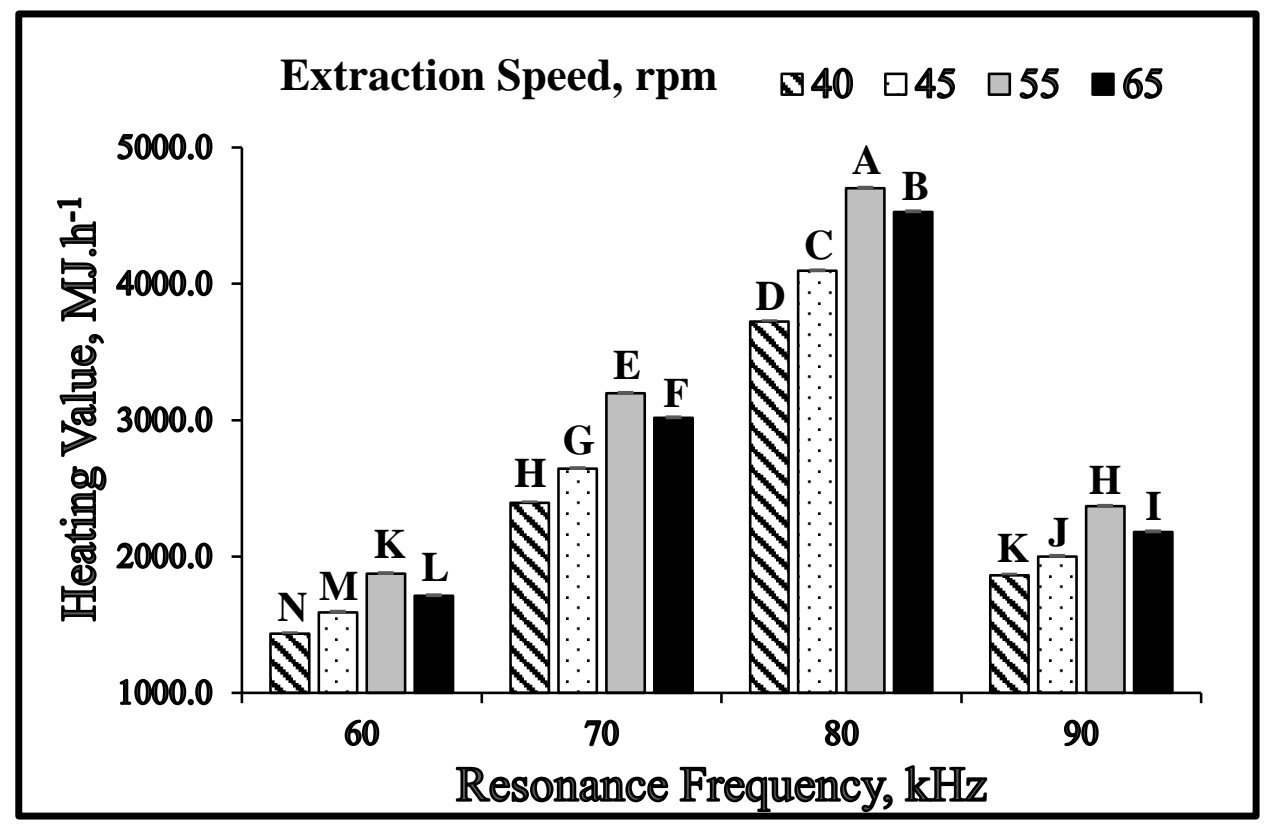

Fig. 6: Effect of frequency levels on the heating value under the same differences between means.

The heating value per hour increased by increasing frequency level because of the increase in accelerate the rotation and internal pressure for jojoba seeds leading raise to an increase mass transfer and oil flow on the screw surface at the same time unit. While the decrease effect was attributed to the lower in seeds material inside the extraction area that leads to decrease the amount of oil produced it is followed reducing heating value per hour.

\section{Produced power}

Different treatments highly significant of resonance frequency levels that influenced in produced power as shown in Fig. 7. The obtained results show 
that the resonance frequency levels exhibited highly significant differences ( $\mathrm{P}<0.01$ ) with respect to produce power when the frequency level was increased from 60 to $80 \mathrm{kHz}$ any further increase in frequency level up to $90 \mathrm{kHz}$ the produced power will decrease under different extraction speeds. The maximum values of the produced power were $(1034,1138,1306$ and $1258 \mathrm{~kW}$ ) measured versus $80 \mathrm{kHz}$ frequency level. While the lowest values recorded $(398,442,521$ and $476 \mathrm{~kW})$ by $60 \mathrm{kHz}$ frequency level at extraction speeds of 40, 45, 55 and $65 \mathrm{rpm}$.

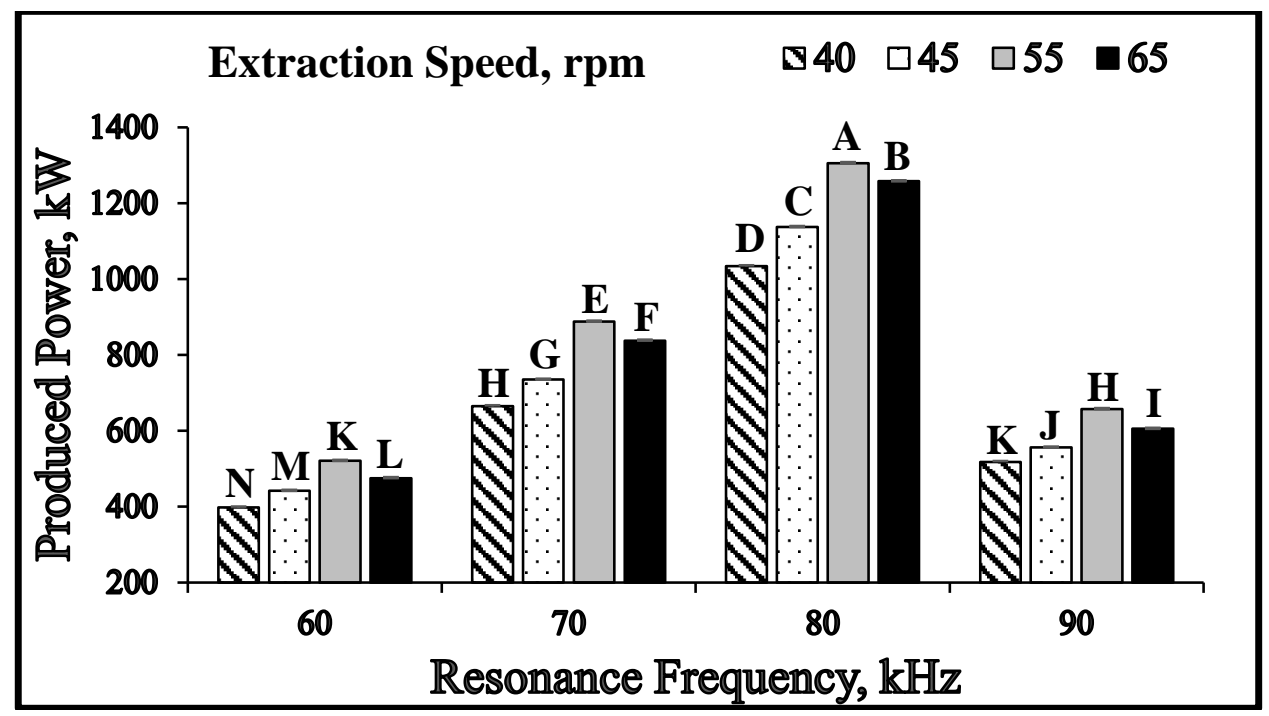

Fig. 6: Effect of frequency levels on produced power. Vertical bars represent the LSD $(P<0.01)$, differences between means with the various letter are highly significant.

The obtained results show that the frequency levels evidenced highly significant effect regarding produce power until proper-frequency level and under different extraction speeds due to increase oil extraction rate at the same corresponding values for energy content.

\section{CONCLUSION}

Overall orientation in this field is to replace fossil fuel by renewable ones eliminating the dangerous environmental pollutants and production of environmentally compatible products which leads to enhance green and sustainable development not only for producing biofuels from renewable 
materials but also to replace a large quantity of conventional products. This study has shown the benefits of application a resonance technique at a frequency from 60 to $90 \mathrm{kHz}$ for enhancing the mechanical extraction process depending on the generated energy is transferred between magnetic and electric fields within the designed circuit supplied with controller unit which leads to oscillation motion mentioned. Potential application of oscillation movement of a resonance technique used to improve oil yield and an extraction efficiency further is significant advance in the economic returns for the jojoba oil as an alternative source of energy. A highly significant increase in the extracted oil yield and overall efficiency was observed in the resonant processing. Both resonant frequency and extraction speed can significantly affect to the evaluation indicators. In relation to a control sample, an additional increment by (34.30 and 26.97\%) of the extraction rate and machine efficiency was noticed consecutively at $80 \mathrm{kHz}$ and adjusting the press screw speed on $55 \mathrm{rpm}$ during treatment.

\section{REFERRENCES}

Al-Hamamre, Z. and K. M. Rawajfeh (2015): Investigating the energy value of jojoba as an alternative renewable energy source. International journal of green energy, 12(4): 398-404.

Amin, T; H. R. Naik, A. H. Rather and I. A. Zargar (2015) Potential applications of ultrasonic in food industry. IJERT, 3(1): 55-61.

Clodoveo, M. L. and H. Hbaieb (2013): Beyond the traditional virgin olive oil extraction systems: Searching innovative and sustainable plant engineering solutions. Food Res. Int; 71:57-62.

Jambrak A. R; D. Lerda, R. Mirceta, M. Simunek, V. Lelas, F. Chemat, Z. Herceg and V. Batur (2012): Experimental design and optimization of ultrasound treatment. Journal of Food Processing \& Technology, 3(3): 1-6.

Soria, A. C. and M. Villamiel (2010): Effect of ultrasound on the technological properties and bioactivity of food: A review. Trends in Food Science \& Technology, 21: 323-31.

Staffell, I. (2011): The Energy and Fuel Data Sheet. University of Birmingham, UK, Cited March. 
Toschi, T. G; A. Berardinelli, C. Cevoli, E. Iaccheri, G. D. Lecce, A. Bendini and L. Ragni (2013): Effectiveness of the mechanical excitation applied to the olive paste: possible improving of the oil yield, in malaxation phase, by vibration systems. Journal of Agricultural Engineering, XLIV:225.

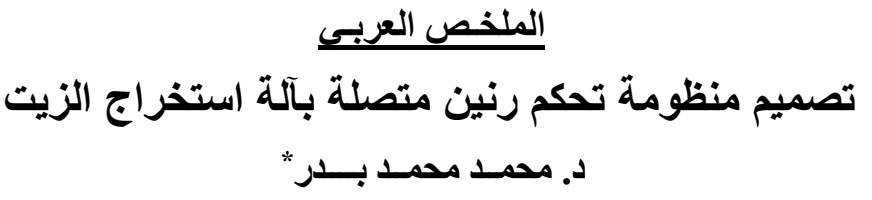

وســــز ايد الطلب على الوقود الحيوى كبديل للوقود الحفرى لتلبية احتباجاتتا من الطاقة، وتفاقم

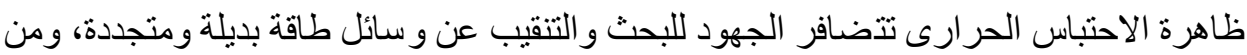

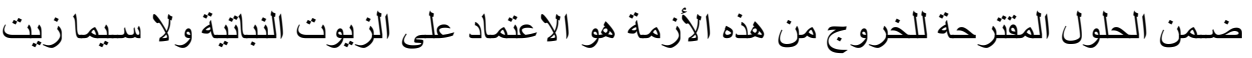

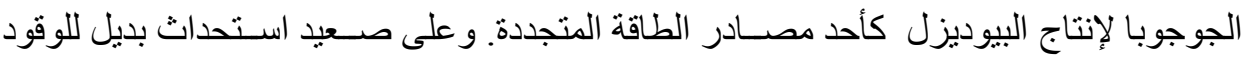

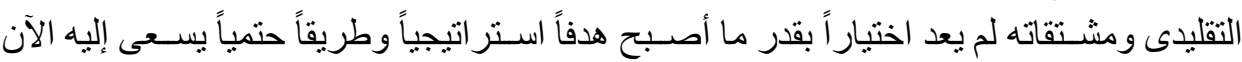

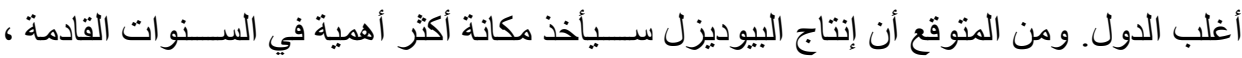

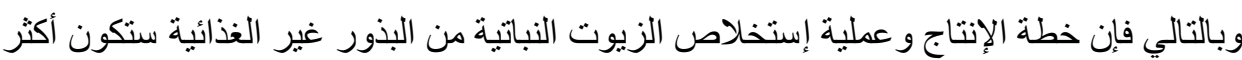

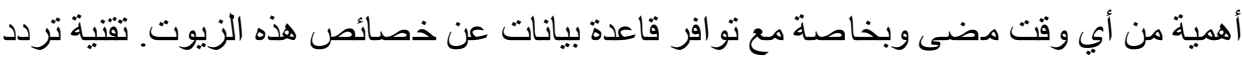

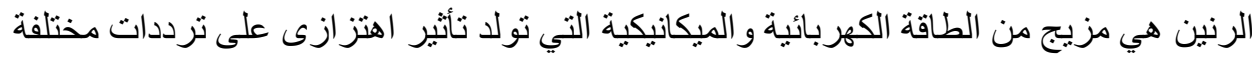

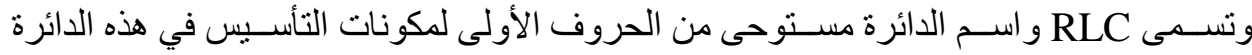

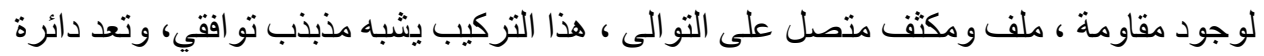

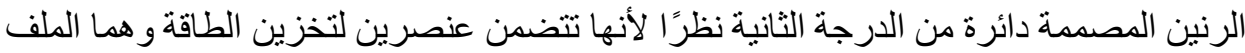

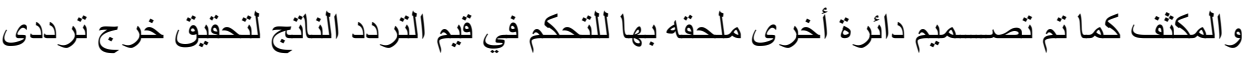

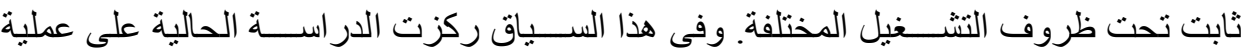

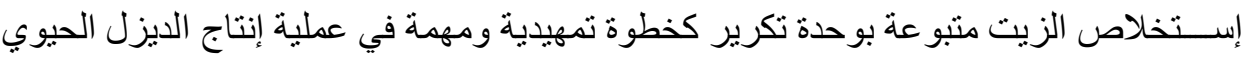

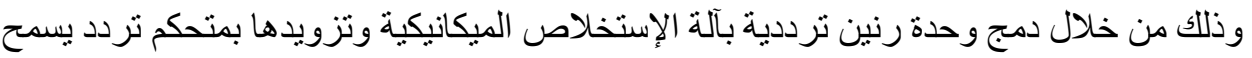

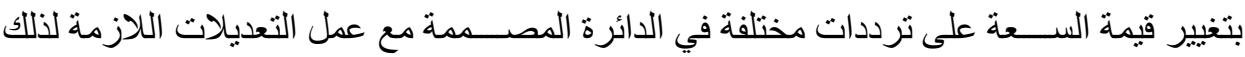

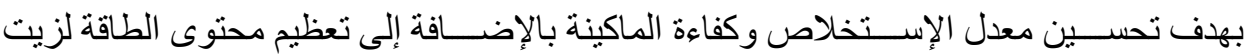

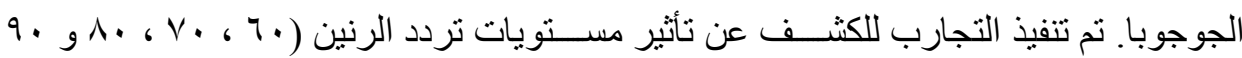

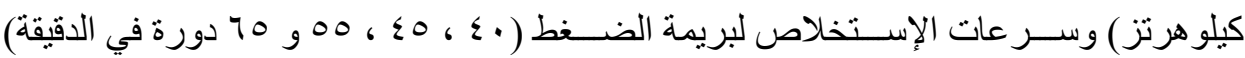

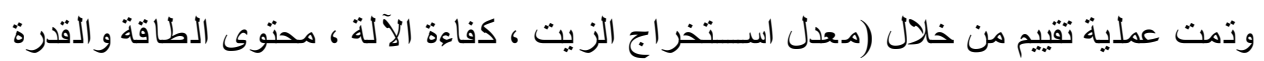

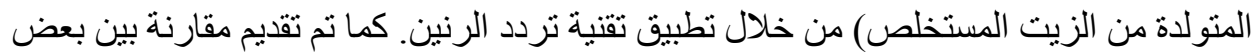
المؤشر ات الرئيسية لمو اصفات زيت الجوجوبا مقارنة بالوقود الديزل و البنزين.

* قسم الهندسة الزراعية - كلية الزراعة - جامعة الزقازيق - مصر. 


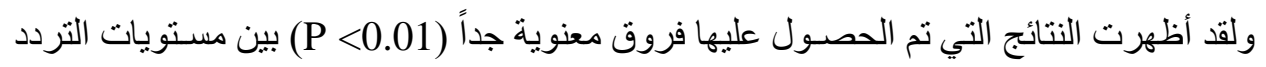

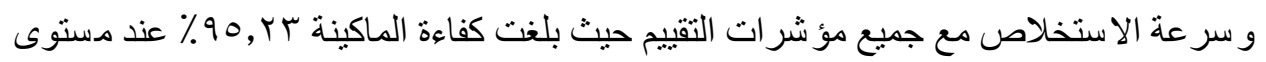

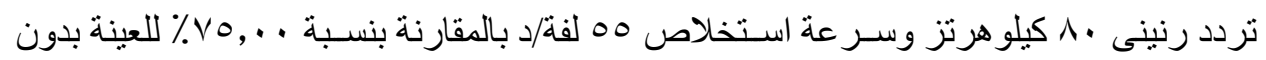

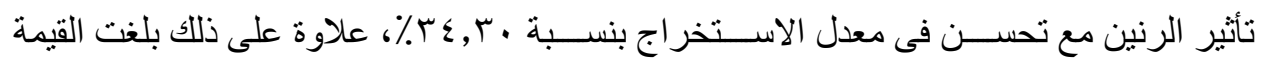

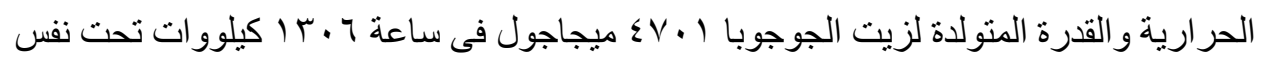

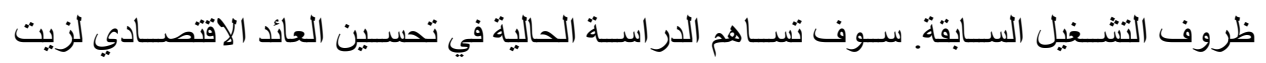

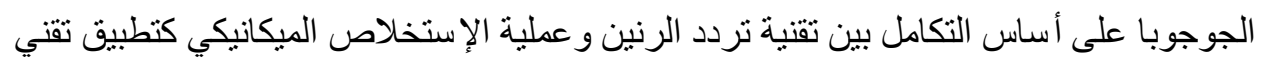

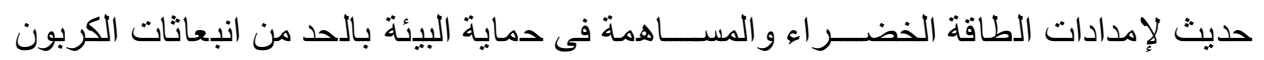
و الإحتباس الحر اري مما يؤدي إلى تعزيز التنمية المستدامة. 